\title{
Effect of sea level extremes on the western Basque coast during the 21 st century
}

\author{
Marta Marcos ${ }^{1, *}$, Guillem Chust ${ }^{2}$, Gabriel Jordà ${ }^{1}$, Ainhoa Caballero ${ }^{3}$ \\ ${ }^{1}$ Mediterranean Institute for Advanced Studies (IMEDEA-UIB-CSIC), Miquel Marquès 21, 07190 Esporles, Spain \\ ${ }^{2}$ AZTI-Tecnalia, Marine Research Division, Txatxarramendi ugartea z/g, 48395 Sukarrieta, Spain \\ ${ }^{3}$ AZTI-Tecnalia, Marine Research Division, Herrera kaia portualdea z/g, 20110 Pasaia, Spain
}

\begin{abstract}
Rising global sea level increases the vulnerability of coastal regions to storm surge flooding. The impact of extreme high waters resulting from the combination of tidal oscillations and changes in mean sea level and in storm surges during the 21st century has been explored in the Bizkaian coast (northern Spain). Mean sea level variations due to temperature changes were estimated from an ensemble mean of global atmosphere-ocean general circulation models in the Bay of Biscay under A1B and A2 climate change scenarios. Changes in the frequency and intensity of storm surges were obtained from the output of a barotropic regional ocean model forced by greenhouse gas concentrations during 2000-2100. The storm surge model was calibrated using available tide gauge observations. Based on the above estimations, return levels of total sea level extremes are expected to increase by up to $40 \mathrm{~cm}$ with respect to present-day values. The likely impacts of resulting floods on coastal and estuarine habitats of the Bizkaian coast were assessed applying the return levels to a high precision light detection and ranging (LiDAR) based Digital Terrain Model. Results show that during the second half of the 21st century up to 202 ha are under risk of flooding, of which $50 \%$ correspond to urbanized land including industrial and residential areas. This represents a more than 3 -fold increase compared to the area at risk from present sea level extremes. This study provides insight into both regional sea level variability and local floodrisks, and thus provides inputs for the formulation of effective mid-term adaptation measures to sea level extremes.
\end{abstract}

KEY WORDS: Sea level · Extremes $\cdot$ Climate change $\cdot$ Storm surges $\cdot$ LiDAR $\cdot$ Coastal impacts

\section{INTRODUCTION}

Sea level changes are a key factor for the development, management and protection of the coastal environment. It is thus essential from ecological, social and economic points of view to understand the causes of sea level variability at different spatial and temporal scales and, as far as is possible, to foresee future changes. Global warming creates additional complexities for projections of sea level variations; outputs of global climate models indicate that mean sea level (MSL) will respond to increased greenhouse gases concentrations by rising between 18 and $59 \mathrm{~cm}$ on average by 2100 due to thermal expansion (IPCC 2007) or possibly even by over $1 \mathrm{~m}$ according to recent semi-empirical models (Rahmstorf 2007, Jevrejeva et al. 2010). This may vary significantly on a regional basis, with some areas experiencing enhanced MSL rise with respect to the global mean. In addition, changes in storminess and thus in sea level extremes are also expected. Although no global consensus has been reached in this respect (IPCC 2007), some recent studies with a regional focus suggest that these changes are plausible. For example, on the basis of a coupled atmosphere-ocean general circulation model (AOGCM), Fischer-Bruns et al. (2005) identified a poleward shift of storm activity at mid-latitudes, with activity increasing over the North Atlantic and Southern Ocean and decreasing over the Pacific Ocean. Debernard \& Roed (2008) found an 
increase in extremes of significant wave height and storm surge residuals in the eastern North Sea and around the British Isles. Marcos et al. (2011) found a decreased occurrence and return levels of storm surge events in the Mediterranean Sea.

The combination of MSL changes and sea level extremes, which, in turn, are caused by the combined effect of tidal oscillations and storm surges, pose important risks especially to low lying areas. Effects could include flooding, beach erosion and intrusion of salt into freshwater rivers, among others (Nicholls \& Leatherman 1994), with associated socioeconomic costs and impacts on coastal ecosystems. The coast of Bizkaia (Basque Country, northern Spain), located in the innermost part of the Bay of Biscay (Fig. 1) is very steep, as is the remainder of the Cantabrian coast. It is dominated by rocky substrata with vertical cliffs and abrasion platforms alternating with small estuaries with sandy beaches at the mouths of rivers (Borja et al. 2004). As a consequence, urban areas on the coast tend to be on low-lying land, and are thus vulnerable to small variations in sea level and in the wave climate (Michael 2007, Vinchon et al. 2009, Chust et al. 2010a).

The goal of this work is to estimate the likely impact of MSL variations and storm surges on the Basque coast during the 21st century, in order to identify flood risk areas. To infer such sea level changes, regional outputs of global climate models have been used to estimate the thermosteric contri- bution to MSL during the 21st century. The mass contribution to MSL has been inferred from the IPCC report (2007). The major novelty of this study is the use of regional projections to estimate the ocean response to potential changes in atmospheric pressure and wind fields, under different climate change scenarios. Thus, no assumption has to be made about the future distribution of sea level extremes during the 21st century. Previous studies either considered that the distribution of storm surge extreme will not change in the future (Marcos et al. 2009, Hunter 2010, Hallegatte et al. 2011), used regional climate models based on downscaled global projections to drive storm surge models (Woth et al. 2006, Debernard \& Roed 2008), or used global models to infer the storm surge component (Cayan et al. 2008). In this study, the combination of projected MSL and storm surge extremes, together with tidal oscillations, has been used to assess the impacts of such changes on the coastal and estuarine habitats of the Bizkaian coast. Since significant vertical land movements have not been reported in the area of study, we did not consider their impacts in the determination of the areas at risk. The use of a light detection and ranging (LiDAR) based digital terrain model (DTM) enabled us to map the flood risk at a high spatial resolution and vertical precision, providing data which can help local managers to devise adaptation measures for this area.

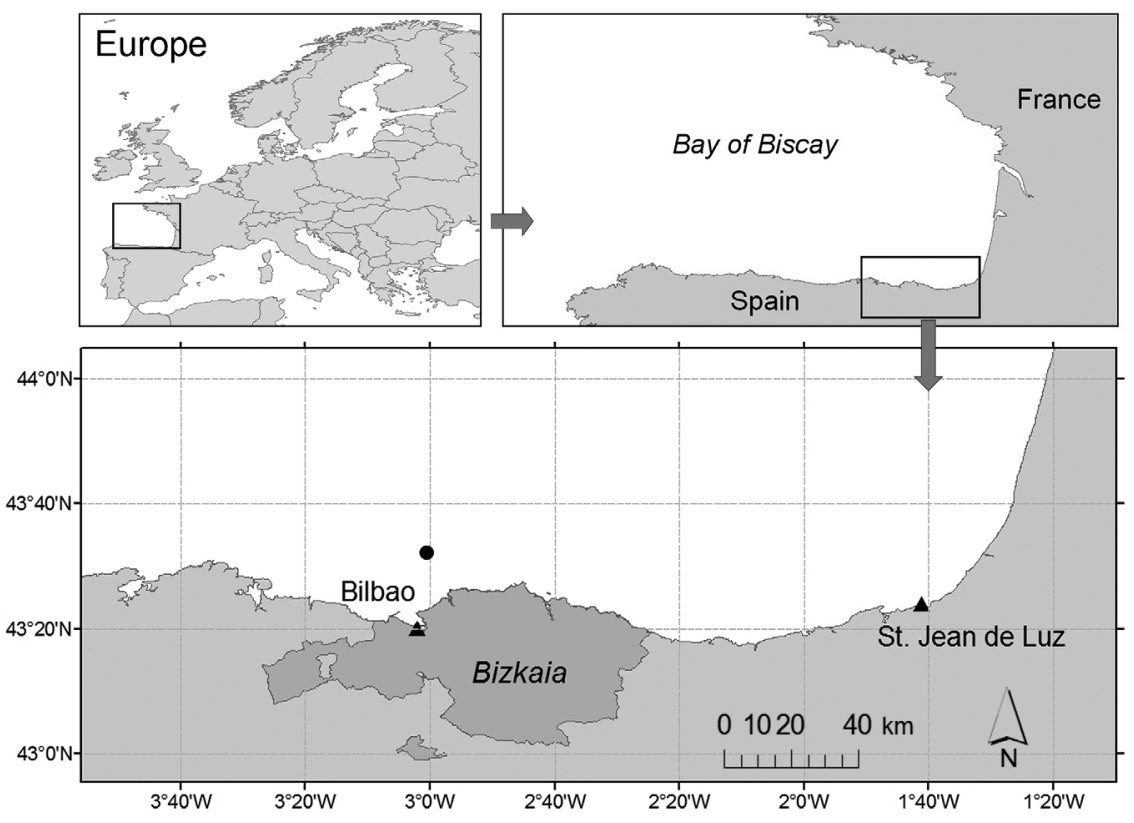

Fig. 1. Bizkaian coast. The locations of the Bilbao tide gauge and Saint Jean de Luz GPS station (triangles) and its closest grid point (circle) from the storm surge model are indicated in the map

\section{DATA SETS}

\subsection{Mean sea level projections for the 21 st century}

Global MSL changes are mainly driven by 2 mechanisms: freshwater addition/subtraction from glaciers, ice caps and ice sheets and thermal expansion/contraction of the ocean waters. According to the IPCC (2007), the mass contribution to global sea level rise by 2100 will be between 4 and $20 \mathrm{~cm}$. Notably, this contribution presents a large range of uncertainty, due to the short periods of observations available and especially due to the inaccurate modelling of ice dynamics (i.e. the dynamic instabilities in ice-bound areas driving coastal water flow into the ocean). These estimates, although they represent the 
published consensus view (IPCC 2007), are likely to be a lower bound (Cazenave \& Llovel 2010). In this study and as a conservative approach we use $20 \mathrm{~cm}$ as the value for the mass contribution by 2100 . Regionally, the action of atmospheric pressure and wind also play a role in MSL variation.

Thermal contribution to MSL has been estimated by an ensemble of AOGCMs available through the World Climate Research Programme (WCRP, wwwpcmdi.llnl.gov/ipcc/about_ipcc.php). The models are forced with concentrations of greenhouse gases (GHG) and aerosols derived from various emission scenarios. Monthly global fields of ocean temperature ( $T$ ) have been downloaded for the 20th century (1950-2000) and for A1B and A2 scenarios for the period 2000-2099 (see Table 1). For the 20th century scenario the models are forced with historical concentrations of GHG; hereinafter these simulations will be referred to as the control run. Additionally, a preindustrial control run, which is forced with GHG concentrations corresponding to a pre-industrial era, has been downloaded for each model. It has been used to correct possible internal drifts of individual models.

Following Chust et al. (2010a) a sector corresponding to the Bay of Biscay $\left(43^{\circ} \mathrm{N}-48^{\circ} \mathrm{N}, 1^{\circ} \mathrm{W}-8^{\circ} \mathrm{W}\right.$; Fig. 1) has been selected for each model. As pointed out by Chust et al. (2010a), not all the models are run for all scenarios and additionally some show anomalous behaviour in the region. Taking these limitations into account, from the initial 23 models downloaded 10 were selected for this study: bccr_bcm2, cccma cgcm3, cccma_cgcm3_1, cnrm_cm3, csiro_mk3_5, csiro_mk3_5, giss_model_e_h, iap_fgoals1,_mri_ cgcm2_3_2a and ukmo_hadcm3 (Chust et al. 2010a).

At each grid point of each model the monthly thermosteric sea level has been computed by calculating the vertical integral of the specific volume anomaly caused by changes in $T$ (assuming constant salinity) from the sea surface down to the bottom. The regional MSL change due to variations in ocean water density was then computed by averaging thermosteric sea level over the Bay of Biscay for each model. In order to remove possible internal drifts of the AOGCMs, the linear trends obtained from the pre-industrial control runs were subtracted for each model and scenario. Finally, for each scenario and for the control run the mean of the multi-model ensemble of monthly time series was calculated and taken as our best estimate of regional mean thermosteric sea level changes in the region. The uncertainties are estimated as the standard deviation of the multi-model ensemble. Fig. 2 represents the contributions of MSL changes during the 21st century under A1B and A2 scenarios.

\subsection{Storm surge model: hindcast and projections for the 21st century}

The storm surge contribution to sea level was obtained from regional simulations of the HAMSOM ocean circulation model (Backhaus 1985). This model was implemented, in its barotropic (2D) mode, covering the whole Mediterranean Sea and a northeastern sector of the Atlantic Ocean with a spatial resolution of $1 / 4^{\circ}$ and $1 / 6^{\circ}$ in latitude and longitude, respectively. Note that tidal forcing was not included. The model configuration was almost the same used by Ratsimandresy et al. (2008), although in our case it was forced 6-hourly by $10 \mathrm{~m}$ winds and atmospheric Sea Level Pressure (SLP) provided by the ARPEGE-v4 climate model. ARPEGE is a global and spectral atmospheric general circulation model whose grid can be stretched over the area of interest. In this case, a version with a pole located in the Tyrrhenian Sea and a resolution of $\sim 50 \mathrm{~km}$ over the Mediterranean Basin was used. The model runs used in this work are summarized in Table 1. A detailed description can be found in Jordà et al. (2012) and Marcos et al. (2011), but the main points will be summarized here for completeness. The hindcast run is obtained by forcing the HAMSOM model with the ARPEGE dynamical downscaling of ERA40 reanalysis (Uppala et al. 2005) for the period 1958-2001. In this downscaling, the large scales of ARPEGE model are forced to follow the synoptic chronology of ERA40 by using a spectral nudging technique (Kaas et al. 1999). Namely, surface temperature, air temperature, surface pressure,

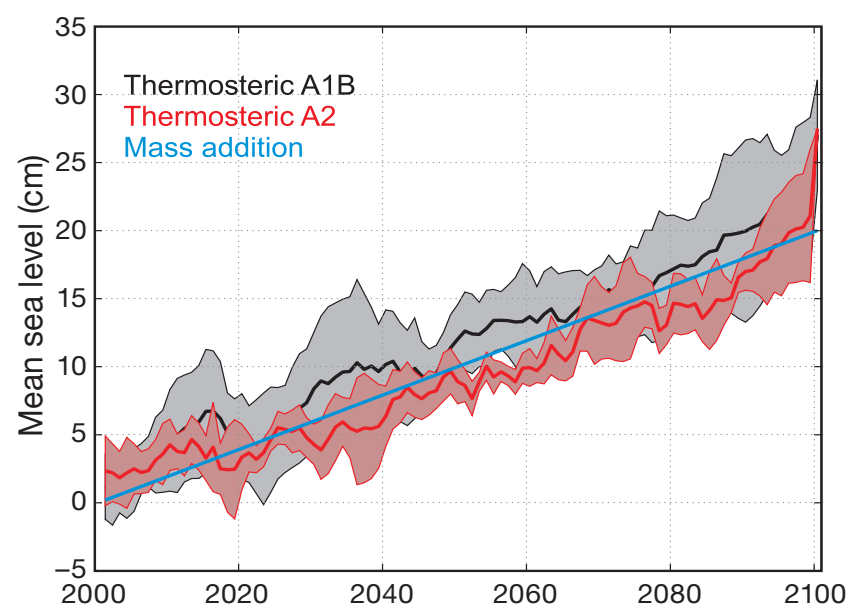

Fig. 2. Yearly time series of the thermosteric contribution to mean sea level (MSL) changes, during the 21st century in the Bay of Biscay under A1B and A2 scenarios and the corresponding standard deviations of the multi-model ensembles. Mass addition from melting land ice with a maximum of $20 \mathrm{~cm}$ by 2100 is also plotted 
Table 1. Numerical simulations used in this study, and their forcing, contributions and periods. GHG: greenhouse gas

\begin{tabular}{|llll|}
\hline Simulation & \multicolumn{1}{c|}{ Atmospheric forcing } & \multicolumn{1}{c|}{ Contributions } & Period \\
\hline Hindcast (calibrated) & Dynamical downscaling of ERA40 & Storm surge hindcast (calibrated) + tides & $1958-2001$ \\
Control & Observed GHG concentration & Storm surge control + tides & $1950-1999$ \\
A1B & Moderate GHG concentration & Storm surge A1B + tides + thermosteric A1B + mass & $2000-2099$ \\
A2 & High GHG concentration & Storm surge A2 + tides + thermosteric A2 + mass & $2000-2099$ \\
\hline
\end{tabular}

wind divergence and vorticity are nudged towards the $6 \mathrm{~h}$ outputs of the ERA40 reanalysis. Small scales $(<250 \mathrm{~km})$ and the specific humidity are allowed to vary freely. This hindcast is considered as the best approximation to the present climate; Jordà et al. (2012) found correlations with tide gauges (after removing the tidal signal) larger than 0.75 and RMS differences lower than $3.5 \mathrm{~cm}$ in most stations over the entire domain. In particular, for Bilbao tide gauge the variance reduction was found to be $82 \%$.

In the control run, the forcing consists of observed greenhouse gas (GHG) concentrations for the period 1950-2000. The control run was compared with the hindcast run with the aim of determining the extent to which a simulation forced only by GHG concentrations (i.e. without any data assimilation) was realistic. Jordà et al. (2012) found that the control run was in good agreement with the hindcast at low frequencies. The energy and the spatial patterns of sea level variability at monthly, seasonal and inter-annual frequencies were very similar between both runs. Moreover, the observed correlation with climate indices such as NAO was also well reproduced in the control run. Concerning extreme events, Marcos et al. (2011) showed that the comparisons between the hindcast and the control simulation were consistent in terms of mean number, duration and type of both positive and negative storm surges. In addition, the spatial distribution of the magnitude of the extremes was the same in both cases. A second objective of the control run was to provide a reference to which the future projections could be compared. Since the statistics in the control run are in good agreement with the statistics of the hindcast simulation both in terms of the mean regime (Jordà et al. 2012) and the extreme events (Marcos et al. 2011), we consider that the results of the scenario simulations will be representative of the impact of increased GHG concentrations on sea level changes caused by atmospheric forcing. We thus assume that impacts of GHGs concentrations are reflected in regional changes in atmospheric pressure and wind. Finally, projections for climate change scenarios for the 21st century were calculated under the A1B and A2 emission sce- narios for the period 2000-2099 using their respective GHG concentrations as defined by the IPCC (2000).

\subsection{The LiDAR-based digital terrain model}

A high-resolution DTM of the Bizkaian coast (available from www.geo.euskadi.net/s69-15375/es/) was used. The DTM was generated from an airborne LiDAR system (Wehr \& Lohr 1999) in 2008, and it had a $1 \times 1 \mathrm{~m}$ horizontal resolution derived from a density of 2 laser measurement points per $\mathrm{m}^{2}$ and a vertical accuracy of $0.15 \mathrm{~m}$ RMS. Specifically, the ground (bare-earth) model (i.e. removing objects such as trees and shrubs, and eliminating bridges, whilst keeping buildings) was used. DTM values were in orthometric heights (MSL of Alicante Datum), obtained using the IBERGEO95 geoid model, and the ETRS89 coordinate reference system. The Alicante Datum, the reference used in Spain, is $0.34 \mathrm{~m}$ below the MSL in Bilbao, according to the vertical levelling of 2008 (Puertos del Estado 2009).

\section{METHODOLOGY}

We aimed to estimate return levels of extreme sea level events during the 21st century caused by the combined action of storm surges, tides and MSL rise on the coast of Bizkaia. To do so, we first calibrated the storm surge model using sea level observations from a tide gauge (Section 3.1). Then (Section 3.2) the projected storm surges in combination with tidal oscillations and projected MSL changes were used to build total sea level time series for the 21st century for each climate change scenario. These series were the basis for the estimation of return levels under different climate change scenarios.

\subsection{Storm surge model calibration}

The closest grid point of the storm surge model to the coast of Bizkaia (Fig. 1) was selected as represen- 
tative of the atmospherically-induced sea level in the area of interest. The performance of the model was checked by comparing the output of the hindcast simulation with observed tidal residuals at the tide gauge located in Bilbao for their common period (1992-2001). The Bilbao tide gauge (see Fig. 1 for location) is part of the Spanish tide gauge network operated by the Spanish Ports Authority (Puertos del Estado; www.puertos.es). The tidal oscillations in the area have a semi-diurnal regime, with amplitudes up to $2.5 \mathrm{~m}$ (REDMAR 2005). Almost continuous hourly observations are available for the period since its installation in 1992. The tide gauge measures tidal oscillations, storm surges and the seasonal cycle caused by the seasonal thermal expansion and contraction of ocean waters. In order to isolate the atmospherically-induced component, both the tides and the annual cycle have been removed from the observational record. First, the tidal record has been computed. To do that, tidal constituents with a signal-tonoise ratio equal or larger than 3 have been fitted to the time series by harmonic analysis, using the standard program T_TIDE (Pawlowicz et al. 2002). Time series of tidal residuals were obtained by subtracting the tidal record from the observations. The residual series was then deseasoned by fitting a harmonic annual signal.

Observed (detided and deseasoned) and modelled hourly time series are plotted in Fig. 3a for the period 19932001. The hindcast satisfactorily reproduces the observed tidal residuals with a correlation factor of 0.91 at daily time scale, in agreement with the conclusions reached by Jordà et al. (2012). However, from Fig. 3a it is also evident that the magnitudes of extreme events at the tide gauge site are underestimated by the modelled data by up to several centimetres. This is also shown in Fig. 4a (black crosses), where percentiles of storm surge heights in the observed and model time series are compared for the same period. Higher extremes are smaller in absolute value by more than $10 \mathrm{~cm}$ in the model than in the observations. Differences found in extreme values can be attributed to 3 factors. First, the model grid point is about $2.7 \mathrm{~km}$ away from the location of tide gauge on the coast; therefore, recorded storm surge waves may be subject to local amplification of the coastal bathymetry not reproduced by the model. Second, the limited resolution of the atmospheric model may misrepresent the effect of local winds. And finally, the differences may (at least partly) be because the non-linear interaction between tides and surges was not taken into account.

To take account of the underestimation of the extreme sea levels and be representative of the actual values reached at the coast of Bizkaia, the hindcast run of the storm surge model needs to be calibrated. First, we constructed a quantile-quantile plot, showing the percentiles from the 0.01th up to the 99.99th of the model output and the (detided and deseasoned) observations (Fig. 4a). This shows how the model underestimates the observed magnitudes, with larger underestimations of higher sea level values. Fig. $4 \mathrm{~b}$ displays these differences as a function of the storm surge value in the model for the period 19932001. We then calibrated the storm surge model by adding the corresponding difference to each hourly value for the entire period of the hindcast, 1958-

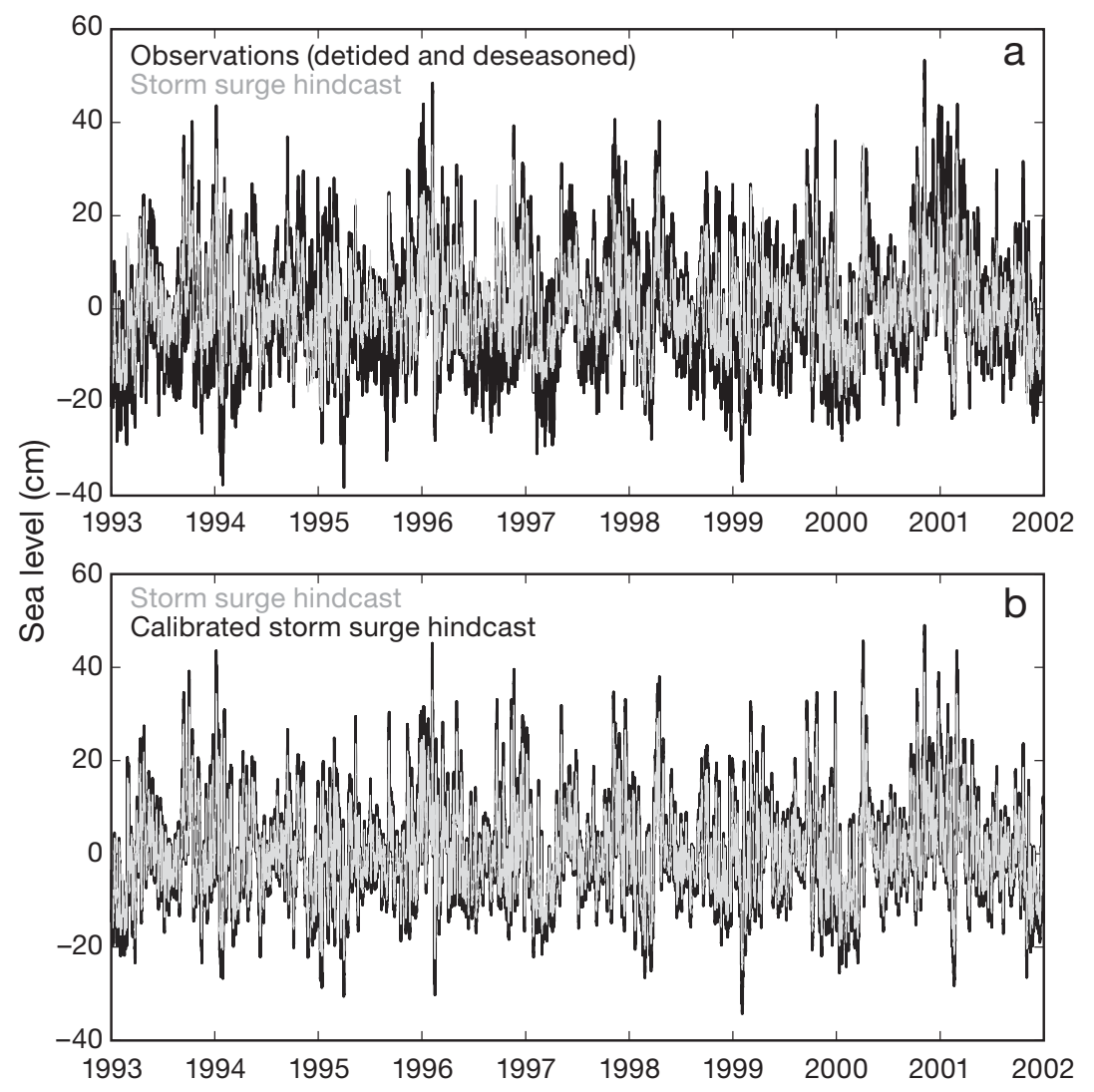

Fig. 3. (a) Hourly observations (detided and deseasoned) at Bilbao tide gauge (black) and storm surge hindcast (grey) time series at the closest grid point of the Bizkaian coast. (b) Calibrated (black) and non-calibrated (grey) storm surge hindcast at the same grid point 

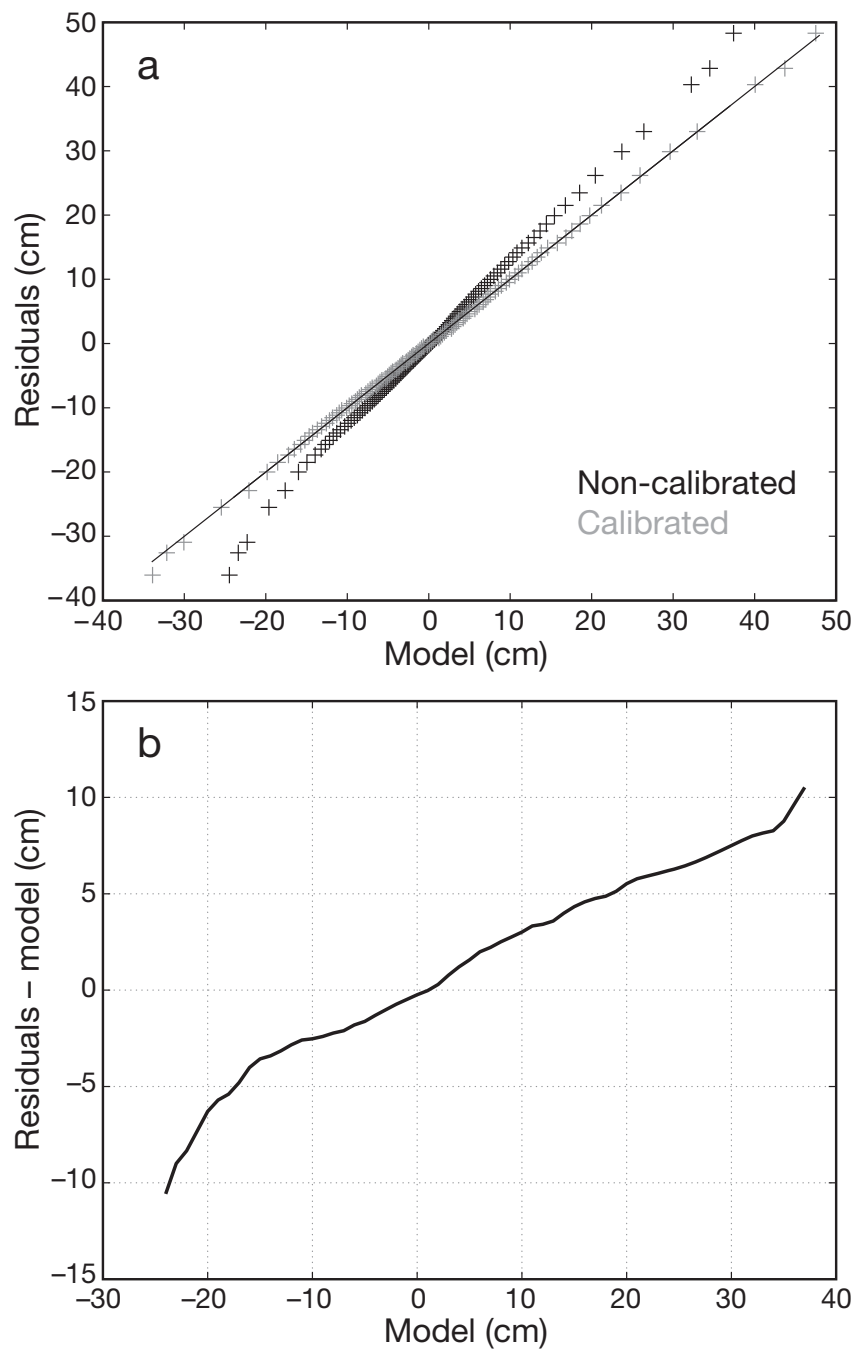

Fig. 4. (a) Percentiles of the hindcast (black) and calibrated hindcast (grey) of the storm surge model versus the detided and deseasoned observations (residuals). (b) Differences between hindcast and (detided and deseasoned) observations as a function of the modelled value

2001. In other words, the modelled surge magnitude of the hindcast was used to calculate the corresponding conditional bias, which was then applied to give the calibrated prediction. The resulting percentiles of the calibrated hindcast compared to those of the observations were plotted in Fig. 4a (grey points). The correspondence for extremes clearly improved as a result of applying the calibration. The resulting calibrated hindcast was considered as the best representation of the storm surge at the coast of Bizkaia during the second half of the 20th century. The same calibration procedure was applied to storm surge control and the scenarios. This seems to confirm the assumption that the biases between model and observations are unaffected by climate change.

\subsection{Total sea level time series and extreme analysis}

Hourly total sea level time series were built for the 21st century, under the assumption of climate change scenarios, by adding the contributions of the storm surges, tidal oscillations and MSL changes. We recall here that a single storm surge run was carried out for each scenario, and that the MSL contribution for each climate change scenario was estimated as the mean of the corresponding multi-model ensemble. Additionally, 2 more time series combining storm surges and tides were also built for the period 19602000 using the storm surge control run and the hindcast simulation, respectively. This approach disregards the interaction between storm surges and the water depth increase due to MSL rise, given the narrowness of the continental shelf and the mean depth of the model bathymetry $(10 \mathrm{~m})$, which is much larger than the projected MSL rise. A summary of the time series of total sea level and the corresponding contributions and periods run is shown in Table 1.

The tidal contribution was built on the basis of the main tidal constituents computed for the tide gauge in Bilbao for its available period of operation 19922004. The generated hourly tidal time series spans the period 1960-2099.

Calculated MSL changes incorporate both thermosteric contribution and mass addition from melting land ice during the 21st century (Fig. 2). The standard deviations provided by the multi-model ensemble of AOGCMs were also used in the projected time series as a source of uncertainty.

The extreme distribution of total sea level was obtained by modelling the $r$-largest surge events per year using the joint probability distribution function (Tawn 1988):

$G\left(x_{i}\right)=\exp \left[-\left(1+\zeta \frac{x_{i}^{(r)}-\mu}{\sigma}\right)^{-1 / \zeta}\right] \prod_{k=1}^{r} \frac{1}{\sigma}\left[1+\zeta \frac{x_{i}^{(k)}-\mu}{\sigma}\right]^{\frac{-1}{\zeta}-1}$

where $\mu, \sigma$ and $\zeta$ are the location, scale and shape parameters, respectively and $\left(x_{i}^{(1)}, \ldots, x_{i}^{(r)}\right)$ with $x_{i}^{(1)}>x_{i}^{(2)}>\ldots>x_{i}^{(r)}$ are the $r$ maxima values for year $i$. Each event $x^{(\mathrm{k})}$, with $k$ varying from 1 to $r$, must be independent from the others and thus separated by a time threshold, which in this case is taken as $72 \mathrm{~h}$. This methodology assumes independent and identically distributed variables.

The location, scale and shape parameters were estimated by fitting the theoretical distribution to the empirical one by maximizing the following loglikelihood function: 
$l=r N \log \left(\frac{1}{\sigma}\right)$
$+\sum_{i=1}^{N}\left[-\left(1+\zeta \frac{X_{i}^{(r)}-\mu}{\sigma}\right)^{-1 / \zeta}+\sum_{k=1}^{r}\left[\left(\frac{-1}{\zeta}-1\right) \log \left(1+\zeta \frac{X_{i}^{(k)}-\mu}{\sigma}\right)\right]\right]^{(2)}$

where $N$ is the number of years. The $M$-year return level $(R L)$, defined as the probability of a given value to be exceeded once every $M$ years, was calculated using the estimated parameters, and is given as:

$$
R L=\mu-\frac{\sigma}{\zeta}\left(1-\left[-\log \left(1-\frac{1}{M}\right)\right]^{-\zeta}\right)
$$

In the estimation of return levels from total sea level time series, the 3 largest events per year of simulation and separated by at least $72 \mathrm{~h}$ were selected. Two $40 \mathrm{yr}$ periods during the 21st century, namely 2010-2050 and 2060-2100, were chosen as indicative of changes during the 2 halves of the century for each scenario A1B and A2. These results were compared with present-day values, as provided by the control time series (see Table 1) for 1960-2000. Relative changes in return levels are defined as the differences between the values obtained for the climate scenarios and for the control run. Return levels are defined as the addition of these relative changes to the values derived using the calibrated hindcast (see Table 1) for the period 1960-2000. Differences between return levels estimated from observations and from the calibrated hindcast were $<2 \mathrm{~cm}$ when their common period was used. The calibrated hindcast has been preferred to the observations for consistency and because of the shorter length of the observed record. Finally, extreme sea level events were used as a basis for the determination of flood risk areas.

\subsection{Flood risk maps}

With the aim of assessing the impacts of the sea level extremes along the coastal and estuarine habitats as well as their extent, the potential area affected by each one of the levels was estimated. This socalled flood risk area was delimited using geographic information systems (GIS) in 2 steps. (1) The coastline defined by the maximum astronomic high tide (MAHT) along the Bizkaian coast (i.e. $2.43 \mathrm{~m}$, with reference to MSL in Bilbao), extracted from the DTM was introduced in the GIS; together with the coastline generated by adding the estimated extreme levels. The area between both coastlines was then delimited. (2) That area was then fused to those inland areas lying below the MAHT that are connected to the aforementioned area. The calculated area is in the orthogonal plane, i.e. without taking into account the slope of the surface. The inundated polygons unconnected to seawater were removed, following Webster et al. (2006). Finally, this flooded area was overlain with a land use classification corresponding to 2008 (available from www1.euskadi.net/udalplan/ visor/). Specifically, a natural (undeveloped) land cover and 4 urbanized land uses were considered: transport networks, municipal facilities, residential and industrial zones.

\section{RESULTS}

\subsection{Return levels of total sea level extremes}

Return levels estimated from total sea level time series (Table 1) for periods between 5 and $100 \mathrm{yr}$ and for the 2 halves of the 21st century at the Bizkaian coast are represented in Fig. 5. The range of values during the 21st century originates from the uncertainties in the thermosteric contribution. The present-day return levels estimated using the calibrated time series are also plotted for comparison.

We recall here that return levels plotted in Fig. 5 were computed as the difference between each scenario and the control run, and added to the estimation from the calibrated hindcast, as explained in Section 3.2. To illustrate the procedure of computing return levels and to show relative changes in return levels as estimated from each total sea level time series, values for $50 \mathrm{yr}$ return levels obtained from the 4 simulations are listed in Table 2. As an example, the largest $50 \mathrm{yr}$ return level is reached under the A1B scenario during the second half of the 21st century with a value of $298 \mathrm{~cm}$. The return level, as plotted in Fig. 5, has been computed as 298 (A1B) 258 (control) +265 (hindcast $)=305 \mathrm{~cm}$. The same has been applied to return periods between 5 and $100 \mathrm{yr}$ with upper and lower limits of return levels estimated under the 2 scenarios.

According to Fig. 5, values reached during the second half of the 21st century are found to be higher than those obtained for the first half. In absolute values, 50 yr return levels for both scenarios range between 296 and $305 \mathrm{~cm}$ above present MSL in Bilbao, that is, between 53 and $62 \mathrm{~cm}$ above present MAHT (which is $243 \mathrm{~cm}$ above present MSL).

Provided that tidal contribution does not vary with time, projected changes in return levels are attributed to 3 different causes: changes in MSL, changes in mean atmospherically-induced sea level and 

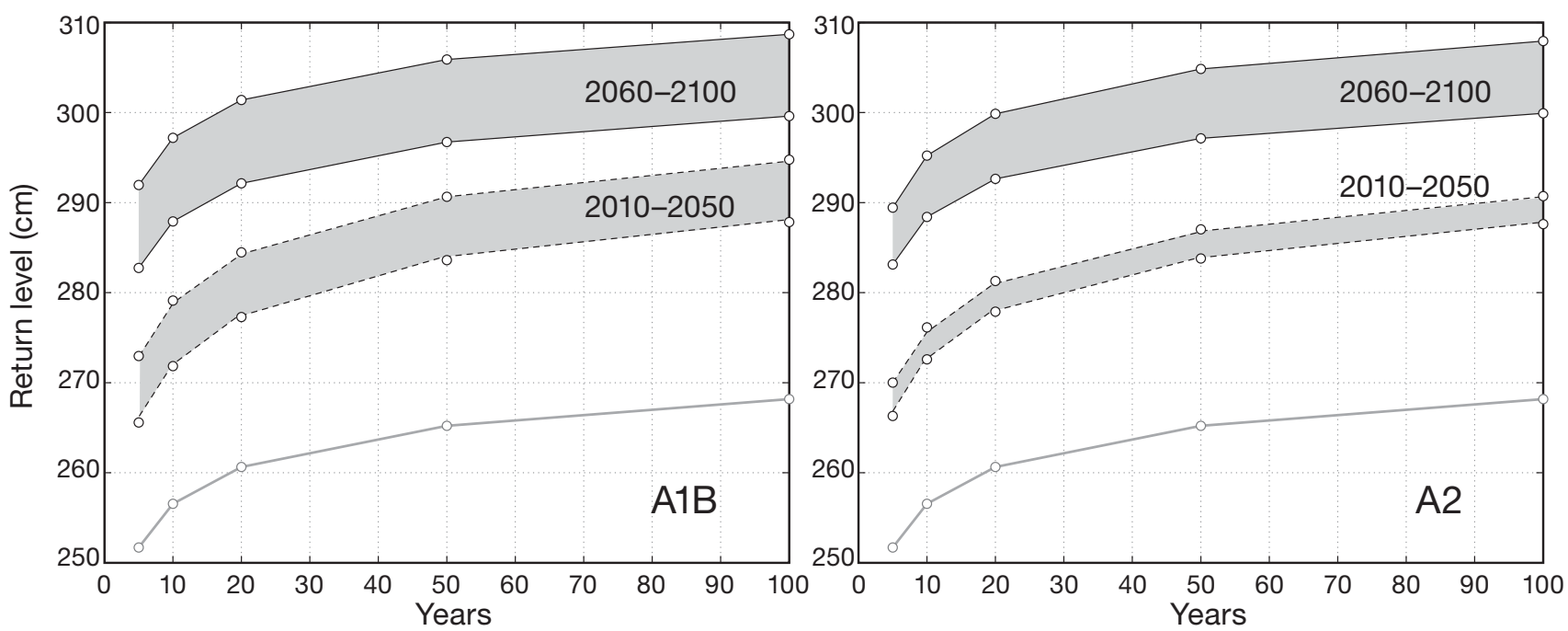

Fig. 5. Return levels of total sea level for the 2 halves of the 21st century under A1B and A2 scenarios. Present-day return levels as estimated from the calibrated hindcast are also plotted (grey lines). Shading: uncertainties in thermosteric contribution

Table 2. Values for 50 yr return levels $(\mathrm{cm})$ based on 20th century time series (1960-2000) and under A1B and A2 scenarios using 21st century time series (2010-2050 and 2060-2100). See Section 3.2 for detailed calculation of the sea level time series and return levels

\begin{tabular}{|lccc|}
\hline Simulation & $1960-2000$ & $2010-2050$ & $2060-2100$ \\
\hline Hindcast (calibrated) & 265 & - & - \\
Control & 258 & - & - \\
A1B & - & $276-283$ & $289-298$ \\
A2 & - & $276-279$ & $289-297$ \\
\hline
\end{tabular}

changes in the intensity and frequency of extreme events.

The impact of changes in MSL was quantified by means of the linear trends of thermosteric sea level for the 21st century under A1B and A2 scenarios and the linear trend of the mass contribution (Table 3). Values are higher for A1B $\left(2.04 \pm 0.02 \mathrm{~mm} \mathrm{yr}^{-1}\right)$ than for A2 $\left(1.77 \pm 0.02 \mathrm{~mm} \mathrm{yr}^{-1}\right)$ in agreement with Chust et al. (2010a). For 50 yr periods, the thermosteric sea level trends account for an increase in sea level extremes of $10 \mathrm{~cm}$ and $8 \mathrm{~cm}$ under $\mathrm{A} 1 \mathrm{~B}$ and $\mathrm{A} 2$, respectively. The mass contribution, if assumed to be linear, adds $10 \mathrm{~cm}$ every $50 \mathrm{yr}$. That is, MSL rises between
18 and $20 \mathrm{~cm}$ every $50 \mathrm{yr}$ in the Bay of Biscay, under $\mathrm{A} 2$ and $\mathrm{A} 1 \mathrm{~B}$ scenarios respectively.

The second source of change was explored using the linear trends of mean atmospherically-induced sea level during the period 2000-2100. Results show that sea level forced by atmospheric pressure and wind presents negative trends under both scenarios (Table 3). Jordà et al. (2012) showed that winter sea level would have a larger negative trend than in summer, when trends would be almost negligible. Thus, a maximum sea level decrease is expected during the season when the strongest sea level extreme events occur. Furthermore, they also investigated the origin of the negative trend in the mean atmospherically-induced sea level. They have found that an increase in the positive phases of the NAO is partially responsible for the trend, especially during the winter season. Absolute values of atmosphericallyinduced MSL trends are an order of magnitude lower than those obtained for the sea level trends (around $-0.34 \mathrm{~mm} \mathrm{yr}^{-1}$ for $\mathrm{A} 1 \mathrm{~B}$ and $-0.4 \mathrm{~mm} \mathrm{yr}^{-1}$ for $\mathrm{A} 2$ in winter). In consequence, they account for a maximum of $-2 \mathrm{~cm}$ decrease in sea level extremes in a 50 yr period under both scenarios considered.

Table 3. Contributions to changes in 50 yr return levels during the 21st century under A1B and A2 scenarios

\begin{tabular}{|c|c|c|c|c|c|c|c|}
\hline & \multirow[t]{2}{*}{$\begin{array}{l}\text { Thermosteric } \\
\left(\mathrm{mm} \mathrm{yr}^{-1}\right)\end{array}$} & \multirow{2}{*}{$\begin{array}{c}\text { Mass } \\
\left(\mathrm{mm} \mathrm{yr}^{-1}\right) \\
2000-2100\end{array}$} & \multirow[t]{2}{*}{$\begin{array}{l}\text { Atmospheric } \\
\left(\mathrm{mm} \mathrm{yr}^{-1}\right)\end{array}$} & \multicolumn{2}{|c|}{$\begin{array}{c}\text { No. of extremes } \\
\left(\text { events } \mathrm{yr}^{-1}\right)\end{array}$} & \multicolumn{2}{|c|}{$\begin{array}{l}\text { Intensity of } \\
\text { extremes }(\mathrm{cm})\end{array}$} \\
\hline & & & & $2000-2050$ & $2050-2100$ & 2000-2050 & $2050-2100$ \\
\hline $\mathrm{A} 1 \mathrm{~B}$ & $2.04 \pm 0.02$ & 2 & $-0.32 \pm 0.01$ & 1.9 & 1.9 & 28.7 & 29.4 \\
\hline $\mathrm{A} 2$ & $1.77 \pm 0.02$ & 2 & $-0.37 \pm 0.01$ & 2.2 & 1.7 & 31.2 & 28.9 \\
\hline
\end{tabular}


Finally, changes in frequency and intensity of extreme events were explored following Marcos et al. (2011). Strong storm surge events have been defined as those events exceeding the 99.5th percentile of the entire time series $(29.1 \mathrm{~cm}$ for A1B and 30.1 for A2) and separated by at least $72 \mathrm{~h}$. Detrended time series were used in order to remove the influence of the mean atmospherically-induced sea level in the identification of surge events. The mean number of strong events per year were computed during the 2 halves of the 21st century (Table 3). Their mean intensity was estimated as the 99.5th percentile for the same 2 periods. The mean intensity for the control run is $29.7 \mathrm{~cm}$ and the mean number of extreme events per year is 2.2. Results indicate that under A1B scenario, the mean number of extreme surges does not change and that their intensity increases slightly by $0.7 \mathrm{~cm}$ during the 21st century. Under A2 scenario, in contrast, the mean number of strong surges per year decreases to 1.7, while their intensity decreases by about $1.5 \mathrm{~cm}$. The mean intensity for the control run is $29.7 \mathrm{~cm}$ and the average number of extreme events per year is 2.2. That is, by the end of the 21st century, both A1B and A2 scenarios project a smaller number of events per year than during the control, but of comparable intensity.

Overall, the results indicate that the main mechanism driving changes in total sea level extremes is the long term MSL rise caused by the thermosteric effect and the mass addition from melting land ice. Atmospherically-induced sea level plays a minor role. In summary, under the A2 scenario, the combined effect of such mechanisms account for a total change of $+16 \mathrm{~cm}$ in $50 \mathrm{yr}(+18 \mathrm{~cm}$ from changes in MSL and $-2 \mathrm{~cm}$ from changes in atmosphericallyinduced sea level, as derived above), which roughly coincides with changes in $50 \mathrm{yr}$ return levels between the 2 halves of the 21st century. Under A1B scenario, there is a similar total change of $+18 \mathrm{~cm}$, of which $+20 \mathrm{~cm}$ are attributed to changes in MSL and $-2 \mathrm{~cm}$ to the atmospheric contribution.

\subsection{Determination of flood risk areas}

The estimated $50 \mathrm{yr}$ return levels were used to determine the flood risk areas for the 2 halves of the 21st century. The highest projected return level - i.e. $305 \mathrm{~cm}$ under the A1B scenario in 2060-2100 (Fig. 5) - was selected to assess potential impacts on coastal habitats and land uses. The present and projected return levels were compared to the sea level of the MAHT along the Bizkaian coast (which is at $243 \mathrm{~cm}$ above the present MSL in Bilbao), in order to map the flood risk of such sea level extreme events. Fig. 6 shows the projected flooded area in the Bilbao conurbation, which is one of the most vulnerable areas at risk of flooding, and in the very populated Barakaldo town. The overall supralittoral area of the Bizkaian coast affected by the sea level extremes has been estimated to be 202 ha, $50 \%$ of which correspond to urbanized land. The most flooded area is concentrated within the estuaries, as expected, since these areas are associated with large and flat plains (mean slope of $5.4^{\circ}$ to $5.8^{\circ}$ ). Industrial areas are the most affected among urbanized land types with 48.1 ha at risk of flooding, followed by residential zones (40.5 ha), transport networks (9.8 ha) and municipal facilities ( $2.3 \mathrm{ha}$ ). The overall future flood risk is more than 3 -fold that expected from the present sea level extreme (Table 4).

Vertical crustal movements can also influence the impacts of sea level on the coastal zone. SantamaríaGómez et al. (2011) provide estimates of vertical velocities from 275 global GPS stations using the most up-to-date analysis. Their closest station to the coast of Bizkaia is located in Saint Jean de Luz (Fig. 1) and presents a vertical velocity of $-0.77 \pm$ $0.70 \mathrm{~mm} \mathrm{yr}^{-1}$ (the relatively large uncertainty in this station is explained by the fact that the record is only 3 yr long; G. Woppelmann pers. comm.). Therefore, vertical land movements have been disregarded.

\section{DISCUSSION AND CONCLUSIONS}

The impacts of sea level changes during the 21st century along the Bizkaian coast were investigated using projections for the different sea level contributions, i.e. MSL changes caused by the thermal expansion of the ocean and the water mass addition from melting land ice, as well as the tidal and the storm surge components. The results indicate that atmospherically-induced sea level in the Bizkaian coast will be reduced during the 21st century due to the increase in mean winter atmospheric pressure over southern Europe. In addition to the positive trend of the winter atmospheric pressure, an increase in the frequency of positive phases of the NAO is expected (i.e. an increase in the pressure difference between medium and high latitudes in the north Atlantic; see Jordà et al. 2012). The effect of the increase in the frequency of positive NAOs on storm surges is a northern shift of the path of the perturbations; consequently in agreement with Jordà et al. (2012) and Marcos et al. (2011), storm surges will affect the region less fre- 


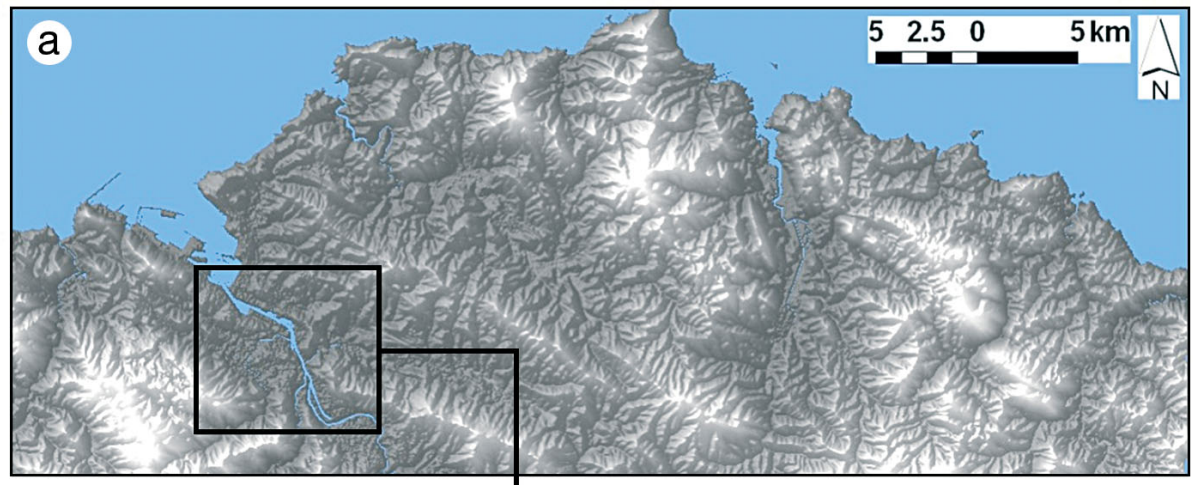

\section{Present sea level extreme}

\section{Future sea level extreme}
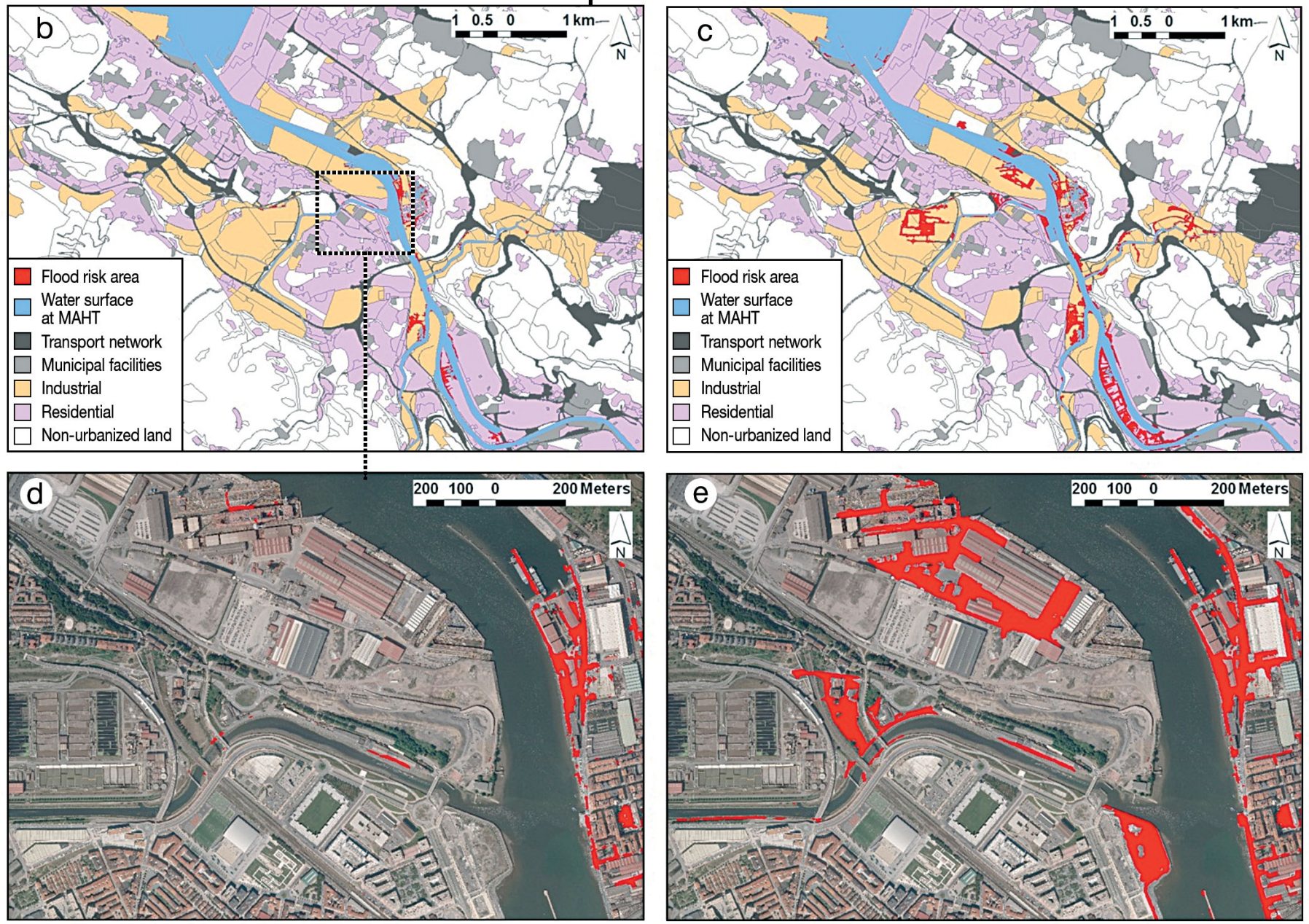

Fig. 6. (a) Shaded relief model of the LiDAR-based Digital Terrain Model (DTM) of the Bizkaian coast. (b-e) Projections of flooded areas (red) corresponding to $(\mathrm{b}, \mathrm{d})$ the present 50 yr return sea level of $265 \mathrm{~cm}$ above present mean sea level and (c,e) the highest projected 50 yr return sea level of $305 \mathrm{~cm}$ (SRES A2) by 2050-2100. (b,c) The Bilbao conurbation area with flooded areas superimposed on land use classification; $(\mathrm{d}, \mathrm{e})$ Barakaldo town with flooded areas superimposed on airborne photography from 2006. MAHT: maximum astronomic high tide

quently. It must be remarked that projected storm surges were derived from a single numerical model and forcing for each scenario. In spite of this, results are consistent with other works that suggest a pole- ward shift of the storms tracks in Europe (Lowe \& Gregory 2005, Fischer-Bruns et al. 2005). An ensemble mean of projections of atmospherically induced sea level would increase the confidence in the results, 
Table 4. Flooded area for each land use of the Bizkaian coast expected for the present and future sea level extremes under A1B scenario. For flood risk, present and future (2050-2100) sea level extremes $=22$ and $62 \mathrm{~cm}$ above maximum astronomic high tide (MAHT), respectively

\begin{tabular}{|c|c|c|c|}
\hline \multirow[t]{2}{*}{ Land use type } & \multicolumn{2}{|c|}{ Flood risk (ha) } & \multirow{2}{*}{$\begin{array}{l}\text { Difference } \\
\text { (ha) }\end{array}$} \\
\hline & Present & Future & \\
\hline Urbanized & 16.6 & 100.7 & 84.1 \\
\hline Transport networks & 1.8 & 9.8 & 8.0 \\
\hline Municipal facilities & 0.5 & 2.3 & 1.7 \\
\hline Industrial areas & 6.5 & 48.1 & 41.6 \\
\hline Residential areas & 7.7 & 40.5 & 32.8 \\
\hline Natural land & 44.4 & 101.0 & 56.6 \\
\hline Total & 61.0 & 201.7 & 140.7 \\
\hline
\end{tabular}

although this contribution is an order of magnitude smaller than the overall projected changes. Therefore, such changes are not critical in the estimation of return levels of total sea level in this region.

Our findings identify long-term MSL changes as the major driver of sea level impacts in the area. The contribution of mass addition to global sea level rise projected for the 21st century plays a major role in changing MSL, as derived from estimations based on the response of surface mass balance to changing air temperatures provided by climate models (IPCC 2007). Using a different approach, some authors have applied semi-empirical models to estimate the relation between variations in global sea level and global air temperatures. Projections in these studies of total sea level rise by the end of the 21st century range between 1 and $2 \mathrm{~m}$ (Rahmstorf 2007, Horton et al. 2008, Vermeer \& Rahmstorf 2009, Jevrejeva et al. 2010), of which about $80 \%$ is attributed to melting of glaciers and ice sheets (Rahmstorf 2010). It is worth noting that rapid dynamical changes in ice flow, which would further increase the global sea level rise, are not included in these projections. If these models are considered plausible, the results presented in this paper provide a conservative scenario of impacts of sea level changes.

Using the projections presented in this work, the extent of flooding induced by sea level extremes expected by 2050-2100 along the Bizkaian coast (estimated as $202 \mathrm{ha}$ ), and especially on urbanized land ( $50 \%$ of that area), is very significant taking into account that most of the 1147476 inhabitants of the province (source: Eustat, www.eustat.es) live near the coast. It is remarkable that this projected area at risk from flooding is more than 3 -fold that expected from the present sea level extreme. Present sea level extremes reach $22 \mathrm{~cm}$ while future reach a maximum of $62 \mathrm{~cm}$ above the present MAHT. Sea level has rarely surpassed the MAHT threshold. When this has occurred, as it last did on 9-10 September 2010, it has provoked some flooding, causing minor disruption to communications. Future flood events can be therefore expected to have much greater impacts, including disruption of human activities and transport, and potential damage to infrastructure. In addition, rising water tables will impede drainage and could induce salinification of groundwater. In terms of ecosystem service loss, the ephemeral flooding that occurs during these extreme events should not significantly affect natural habitats of the region, such as wetlands, sand beaches, vegetated dunes and riparian woods (Chust et al. 2010b). However, these natural habitats may suffer habitat reduction, landward migration or erosion induced by the permanent flooding due to the combined effects of thermosteric and mass contributions to MSL, which is expected to rise by $37 \mathrm{~cm}$ during $2050-2100$ with respect to the present level, as discussed in Chust et al. (2010a).

In comparison to a previous study (Chust et al. 2010a), our study goes one step further in the estimation of future sea level variability due to global climate change by including projections of atmospherically-induced sea level variations. This enables us to determine the intensity and frequency of extreme events, through the use of calibrated model outputs. As a consequence, a more complete data source and a more complex methodology have been applied. This method is easy to reproduce, and could be applied using more accurate climate data as it becomes available in the future.

Finally, it is worth highlighting that this study provides an insight into both regional sea level variability and local flood risk areas, with the aim of providing inputs for mid-term, efficient adaptation measures in response to increasing sea level extremes. The methodology applied here can be extrapolated to any other region worldwide and represents a tool to assess the economic impacts of sea level changes on coastal zones as well as to evaluate the socioeconomic implications of adaptation and mitigation strategies.

Acknowledgements. This project has been supported by the Department of Environment and Regional Planning and by the Industry, Trade and Tourism Department of the Basque Government (K-Egokitzen II project, Etortek Funding Program) and the projects VANIMEDAT-2 (CTM2009-10163C02-01, funded by the Spanish Marine Science and Technology Program and the E-Plan of the Spanish Government) and ESCENARIOS (funded by the Agencia Estatal de METeorología). G.J. acknowledges a 'JAE-DOC' contract funded by the Spanish Research Council (CSIC). M.M. 
acknowledges a 'Ramon y Cajal' contract funded by the Spanish Ministry of Science. The authors acknowledge the contribution of R. Moncho for valuable technical support with LiDAR data processing.

\section{LITERATURE CITED}

Backhaus JO (1985) A three-dimensional model for the simulation of shelf sea dynamics. Deut Hydrogr Z 38: 165-187

Borja A, Aguirrezabalaga F, Martínez J, Sola JC, GarcíaArberas L, Gorostiaga JM (2004) Benthic communities, biogeography and resources management. In: Borja A, Collins $M$ (eds) Oceanography and marine environment of the Basque Country. Elsevier Oceanography Series 70, Elsevier, Amsterdam, p 455-492

> Cayan DR, Bromirski PD, Hayhoe K, Tyree M, Dettinger MD, Flick RE (2008) Climate change projections of sea level extremes along the California coast. Clim Change 87(Suppl 1):S57-S73

> Cazenave A, Llovel W (2010) Contemporary sea level rise. Annu Rev Mar Sci 2:145-173

Chust G, Caballero A, Marcos M, Liria P, Hernández C, Borja A (2010a) Regional scenarios of sea level rise and impacts on Basque (Bay of Biscay) coastal habitats, throughout the 21st century. Estuar Coast Shelf Sci 87: 113-124

Chust G, Grande M, Galparsoro I, Uriarte A, Borja A (2010b) Capabilities of the bathymetric Hawk Eye LiDAR for coastal habitat mapping: a case study within a Basque estuary. Estuar Coast Shelf Sci 89:200-213

Debernard JB, Roed LP (2008) Future wind, wave and storm surge climate in the Northern Seas: a revisit. Tellus 60A: 427-438

- Fischer-Bruns I, von Storch H, González-Rouco JF, Zorita E (2005) Modelling the variability of midlatitude storm activity on decadal to century time scales. Clim Dyn 25: 461-476

Hallegatte S, Ranger N, Mestre O, Dumas P, Corfee-Morlot J, Herweijer C, Wood RM (2011) Assessing climate change impacts, sea level rise and storm surge risk in port cities: a case study on Copenhagen. Clim Change 104:113-137

Horton R, Herweijer C, Rosenzweig C, Liu J, Gornitz V, Ruane AC (2008) Sea level rise projections for current generation CGCMs based on the semi-empirical method. Geophys Res Lett 35:L02715. doi:10.1029/2007 GL032486

Hunter J (2010) Estimating sea-level extremes under conditions of uncertain sea-level rise. Clim Change 99:331-350

IPCC (2000) Special report on emissions scenarios. Cambridge University Press, New York, NY

IPCC (2007) Climate change 2007: the physical science basis. Contribution of Working Group I to the fourth assessment report of the Intergovernmental Panel on Climate Change. Cambridge University Press, Cambridge

Jevrejeva S, Moore JC, Grinsted A (2010) How will sea level respond to changes in natural and anthropogenic forcings by 2100? Geophys Res Lett 37:L07703. doi:10.1029/ 2010GL042947

Jordà G, Gomis D, Álvarez-Fanjul E, Somot S (2012) Atmospheric contribution to Mediterranean and nearby Atlantic sea level variability under different climate change scenarios. Global Planet Change 80-81:198-214

Kaas E, Guldberg A, May W, Déqué M (1999) Using ten- dency errors to tune the parameterisation of unresolved dynamical scale interactions in atmospheric general circulation models. Tellus 51A:612-629

Lowe JA, Gregory JM (2005) The effects of climate change on storm surges around the United Kingdom. Philos Trans R Soc A 363:1313-1328.

> Marcos M, Tsimplis MN, Shaw AGP (2009) Sea level extremes in southern Europe. J Geophys Res 114:C01007. doi:10.1029/2008JC004912

> Marcos M, Jordà G, Gomis D, Pérez B (2011) Changes in storm surges in southern Europe during the 21st century. Global Planet Change 77:116-128

Michael JA (2007) Episodic flooding and the cost of sealevel rise. Ecol Econ 63:149-159

Nicholls RJ, Leatherman SP (1994), Global sea level rise. In: Strzepek K, Smith JB (eds) As climate changes: potential impacts and implications. Cambridge University Press, New York, NY, p 92-123

Pawlowicz R, Beardsley B, Lentz S (2002) Classical tidal harmonic analysis including error estimates in MATLAB using T_TIDE. Comput Geosci 28:929-937

Puertos del Estado (2009) Puerto de Bilbao: nivelación geométrica de alta precisión. http://calipso.puertos.es//BD/ informes/anuales/redmar/REDMAR2009.pdf

Rahmstorf S (2007) A semi-empirical approach to projecting future sea-level rise. Science 315:368-370

Rahmstorf S (2010) A new view on sea level rise. Nat Rep Clim Change 4:44-45

Ratsimandresy AW, Sotillo MG, Carretero JC, Albiach E, Hajji H (2008) A 44-year high-resolution ocean and atmospheric hindcast for the Mediterranean Basin developed within the HIPOCAS Project. Coast Eng 55:827-842

REDMAR (Red de Mareógrafos de Puertos) (2005) Resumen de parámetros relacionados con el nivel del mar y la marea que afectan a las condiciones de diseño y explotación portuaria. http://calipso.puertos.es//BD/informes/ globales/GLOB_NIV_REDMAR.pdf

Santamaría Gómez A, Bouin MN, Collilieux X, Wöppelmann G (2011) Correlated errors in GPS position time series: implications for velocity estimates. J Geophys Res 116:B01405. doi:10.1029/2010JB007701

- Tawn J (1988) An extreme value theory model for dependent observations. J Hydrol (Amst) 101:227-250

Uppala SM, Kållberg PW, Simmons AJ, Andrae U and others (2005) The ERA-40 re-analysis. Q J R Meteorol Soc 131: 2961-3012

Vermeer M, Rahmstorf S (2009) Global sea level linked to global temperature. Proc Natl Acad Sci USA 106: 21527-21532

> Vinchon C, Aubie S, Balouin Y, Closset L, Garcin M, Idier D, Mallet C (2009) Anticipate response of climate change on coastal risks at regional scale in Aquitaine and Languedoc Roussillon (France). Ocean Coast Manag 52:47-56

Webster TL, Forbes DL, MacKinnon E, Roberts D (2006) Flood-risk mapping for storm-surge events and sea-level rise using lidar for southeast New Brunswick. Can J Rem Sens 32:194-211

> Wehr A, Lohr U (1999) Airborne laser scanning - an introduction and overview. ISPRS J Photogramm Remote Sens 54:68-82

> Woth K, Weisse R, von Storch H (2006) Climate change and North Sea storm surge extremes: an ensemble study of storm surge extremes expected in a changed climate projected by four different regional climate models. Ocean Dyn 56:3-15 